\title{
Management of Malignant Phyllodes Tumours of the Breast
}

\author{
Ern Yu Tan*, Huimin Liu, Eileen Shujuan Lai, Sarah Qinghui Lu, Mui Heng Goh, Juliana Jia Chuan Chen \\ and Patrick Mun Yew Chan
}

Department of General Surgery, Tan Tock Seng Hospital, Singapore

Received: February 02, 2018; Published: February 13, 2018

*Corresponding author: Ern Yu Tan, Department of General Surgery, Tan Tock Seng Hospital, 11 Jalan Tan Tock Seng, Singapore 308433, Email: Ern_Yu_Tan@ttsh.com.sg

\begin{abstract}
Background: Malignant phyllodes tumours are rare cancers of the breast. Surgery is the primary mode of treatment and current adjuvant treatments appear ineffective. Survival is extremely poor when distant metastasis develops.

Aim: We retrospectively reviewed 30 women who underwent surgery for malignant phyllodes tumours at our unit over a 16-year period. Clinical outcome, particularly the development of distant metastasis, was examined and factors associated with distant metastasis were evaluated.

Results: Median age was 55 years. All but 2 women presented with a palpable breast mass, which was larger than $10 \mathrm{~cm}$ in 8 . In total, 21 women underwent mastectomy and 9 a wide local excision. Margins remained involved in 4 women even after a mastectomy and 3 received post-operative radiation. Distant metastasis was found in 1 woman on staging scans done in the immediate post-operative period and in another 6 women a median of 5.3 months after surgery. None received chemotherapy and median survival after the development of distant metastasis was 2.2 months. Surgical margin involvement was the only factor associated with distant metastasis $(\mathrm{P}=0.031, \mathrm{OR} 16.499,95 \% \mathrm{CI}$ 0.005 to 0.740 ), but was not significant after adjusting for tumour size ( $P=0.135$, OR $8.348,95 \%$ CI 0.518 to 134.650$)$. Overall survival was 25.5 months and was strongly associated with distant metastasis ( $<<0.001$, HR495.1, 95\% CI 55.84 to 4390 ).
\end{abstract}

Conclusion: Distant metastasis was found in $23 \%$ of women with malignant phyllodes tumours and carried a poor prognosis.

Keywords: Malignant Phyllodes Tumours; Distant Metastasis; Surgery

\section{Introduction}

Phyllodes tumours are uncommon tumours of the breast, the majority of which are benign [1]. Surgical excision is the primary mode of treatment and the tumour is often enucleated since a definitive pre-operative diagnosis of phyllodes tumour is seldom made. Apart from the large size that some tumours can grow to, most phyllodes tumours are indistinguishable from the more common fibroadenoma. There are no pathognomonic clinical or radiological features, and many are reported as fibroepithelial lesions on biopsy [2]. Consequently, the recommended surgical margin clearance of $1 \mathrm{~cm}$ is not often achieved at the initial surgery [3]. A wait and watch approach is often adopted for benign and borderline tumours, even when margins are involved, as metastasis is rare and local recurrences are amendable to further surgery [4]. Malignant phyllodes tumours, however, necessitate more aggressive treatment because of the potential for distant metastasis, which carry an extremely poor prognosis [5].
Malignant phyllodes tumours are uncommon and definitive diagnosis is often only made after histological analysis of the surgical specimen. Treatment involves surgical excision, but with a greater emphasis on obtaining adequate surgical margins. The role of adjuvant treatments remains controversial. In this present study, we retrospectively reviewed a series of malignant phyllodes tumours treated at our unit over a 16-year period. Clinical outcome after definitive surgery was examined. We were particularly interested in the development of distant metastasis and also evaluated factors associated with distant metastasis.

\section{Materials and Methods}

We identified 30 patients who were diagnosed and who underwent surgery for malignant phyllodes tumour at our unit from 1st January 2001 to 31st December 2016. Histological analysis was performed by accredited pathologists at our hospital in accordance with the World Health Organisation (WHO) recommendations [6]. 
A diagnosis of phyllodes tumour was made when the fibroepithelial lesion showed an exaggerated intra-canalicular pattern with leaf-life fronds extending into cystic dilated spaces and stromal hypercellularity. Tumours were graded as malignant when they exhibited marked stromal cellularity and atypia, a high mitotic index of at least 10 per $10 \mathrm{hpf}$ and infiltrative borders. Demographic, clinical, treatment and outcome data were obtained from a prospective database (TTSH/2016-00024). Women who defaulted definitive surgery were excluded from the analyses. The association of distant metastasis with clinicopathological parameters was examined with univariate analyses, using Chi squared test, Chi squared test for trend and Fishers' exact test, where appropriate. Overall survival was examined with Kaplan-Meier survival curves. A 2-tailed $P$ value test was used for all analyses, and a value of $P$ $<0.05$ was considered statistically significant. These tests were performed with GraphPad Prism, version 6 (GraphPad Software, San Diego, CA).

\section{Results}

A total of 30 women with malignant phyllodes tumour were included in this study. Median age was 55 years (ranging from 26 to 75 years); 25 (83.3\%) women were Chinese, 3 (10\%) were Malay, and 2 (6.7\%) were of other ethnicity. The majority of women had presented with a breast lump, ranging in size from $1 \mathrm{~cm}$ to $30 \mathrm{~cm}$. Eight women presented with a mass larger than $10 \mathrm{~cm}$ and ulceration of the overlying skin was present in one woman with a $25 \mathrm{~cm}$ mass. None of the women had clinically palpable axillary nodes, although one was found with radiologically prominent nodes; all nodes removed at axillary dissection were eventually proven negative for metastasis. Only 2 women had presented with a non-palpable screen-detected nodule. Only 1 woman had a preoperative confirmation of malignant phyllodes on biopsy. The initial surgery was an excision biopsy in 7 women (where fibroadenoma was thought the most probable diagnosis) and surgical margins were inadequate (either involved or close, less than $1 \mathrm{~mm}$ ) in all. All 7 women underwent a second surgery ( 4 a re-excision, 3 a mastectomy). Wide local excision was performed in 9 women (suspected of having phyllodes tumour pre-operatively) and 5 required repeat surgery for inadequate margins (1 a re-excision, 4 a mastectomy).

At the second surgery, residual tumour was found in 3 women, all of whom had involved margins at the initial surgery. Residual tumour was not found in any of the 7 women who had close margins. Another 14 women underwent a mastectomy, with 2 opting for immediate autologous transrectus abdominis myocutaneous flap reconstruction at the same setting and 2 requiring coverage of the post-mastectomy defect ( 1 with a vertical rectus abdominis myocutaneous flap and 1 with split skin grafting). Three women who had presented with tumours larger than $20 \mathrm{~cm}$ received chest wall radiation (50Gy in 25 fractions) after margins were still involved after mastectomy; distant recurrence later developed in all 3 women and chest wall recurrence was also present in 2 . Radiation was not offered to women with close or clear margins. Local recurrence developed in 6 women, a median of 3.8 months (ranging from 1.8 to 36 months) after surgery. Two women had involved margins, 1 close margins and 3 clear margins. Only one woman (with clear margins after a mastectomy) did not also develop distant metastasis.

Distant metastasis was found in 7 of 30 women (23.3\%). One woman was diagnosed on staging scans done in the immediate post-operative period and another 6 women relapsed a median of 5.3 months (ranging from 2.1 to 11 months) after surgery. Systemic disease involved the lungs in all 7 women, and also the muscle and subcutaneous tissue in 1 , and also the pericardium, peritoneum and bones in the other. Local recurrence was also present in 5 of the 6 women with distant recurrence and preceded the diagnosis of distant recurrence in 2 patients. Involved surgical margins were the only factor associated with distant metastasis ( $\mathrm{P}=0.031, \mathrm{OR} 16.499$, 95\% CI 0.005 to 0.740 ) (Table 1), but were no longer significant after adjusting for tumour size ( $\mathrm{P}=0.135$, OR $8.348,95 \% \mathrm{CI} 0.518$ to 134.650). Women with distant metastasis tended to have larger tumours, but this did not reach statistical significance $(P=0.068)$.

Table 1: Univariate analyses of the association of distant metastasis with clinicopathological parameters $(n=30)$.

\begin{tabular}{|c|c|c|c|}
\hline Parameter & $\begin{array}{c}\text { Women } \\
\text { with distant } \\
\text { metastasis }(n=7)\end{array}$ & $\begin{array}{l}\text { Women with no } \\
\text { distant metastasis } \\
(\mathrm{n}=23)\end{array}$ & $P$ value \\
\hline $\begin{array}{l}\text { Median age } \\
\text { (years) }\end{array}$ & $53(47-75)$ & $56(26-66)$ & 0.478 \\
\hline $\begin{array}{l}\text { Median tumour } \\
\text { size }(\mathrm{mm})\end{array}$ & $100(30-400)$ & $45(10-300)$ & 0.068 \\
\hline $\begin{array}{l}\text { Surgical } \\
\text { margins }\end{array}$ & 3 & 21 & \\
\hline Clear & 1 & 1 & 0.004 \\
\hline $\begin{array}{c}\text { Close } \\
\text { Involved }\end{array}$ & 3 & 1 & \\
\hline $\begin{array}{c}\text { Stromal } \\
\text { hypercellularity }\end{array}$ & 1 & 0 & \\
\hline Mild & 0 & 3 & 0.280 \\
\hline $\begin{array}{l}\text { Moderate } \\
\text { Marked }\end{array}$ & 2 & 9 & \\
\hline $\begin{array}{c}\text { Stromal atypia } \\
\text { Mild } \\
\text { Moderate } \\
\text { Marked }\end{array}$ & $\begin{array}{l}0 \\
2 \\
2\end{array}$ & $\begin{array}{l}0 \\
7 \\
6\end{array}$ & 0.893 \\
\hline $\begin{array}{c}\text { Stromal } \\
\text { overgrowth } \\
\text { Present } \\
\text { Absent }\end{array}$ & $\begin{array}{l}5 \\
1\end{array}$ & $\begin{array}{c}14 \\
3\end{array}$ & 0.957 \\
\hline $\begin{array}{c}\text { Median number } \\
\text { of mitoses per } \\
10 \mathrm{hpf}\end{array}$ & $20(10-35)$ & $14(7-57)$ & 0.229 \\
\hline $\begin{array}{c}\text { Borders } \\
\text { Infiltrative } \\
\text { Circumscribed }\end{array}$ & $\begin{array}{l}3 \\
0\end{array}$ & $\begin{array}{c}13 \\
3\end{array}$ & 0.414 \\
\hline
\end{tabular}


No association was found between tumour size and stromal hypercellularity $(\mathrm{P}=0.142)$, atypia $(\mathrm{P}=0.978)$ or mitotic index ( $\mathrm{P}$ $=0.457$ ). Six of the 7 women with distant metastasis had died by the end of the study period; the only surviving woman had been diagnosed only one month prior. None of the women with distant metastasis received chemotherapy and median survival after the diagnosis of metastasis was 2.2 months (ranging from 0.1 to 9.3 months). Overall survival in this group of 30 women was 25.5 months (ranging from 1 to 199 months); 9 women had survived longer than 5 years and 3 longer than 10 years. Survival was strongly associated with the development of distant metastasis ( $\mathrm{P}$ $<0.001$, HR495.1, 95\%CI 55.84 to 4390) (Figure 1).

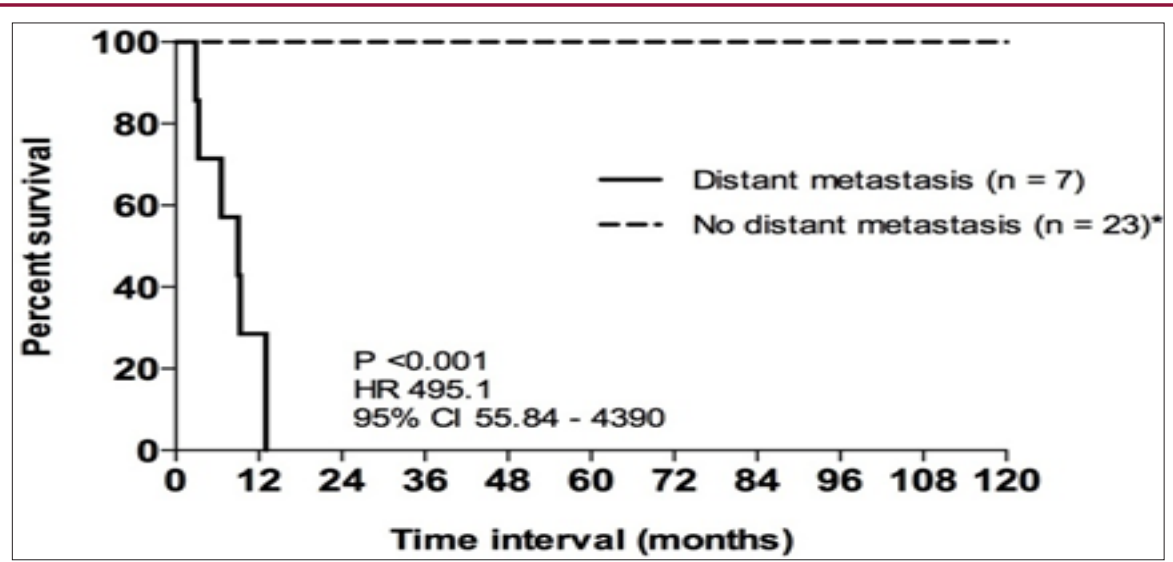

Figure 1: Kaplan-Meier curve depicting overall survival in women with malignant phyllodes tumours stratified by distant metastasis $(\mathrm{n}=30)$. *includes 1 patient with isolated local recurrence (overall survival 110.07 months).

\section{Discussion}

The potential for distant metastasis is the single most worrisome factor for malignant phyllodes and occurs in $10 \%$ to 28\% [7-9]. Like others, we found the lungs to be most frequently involved, in keeping with the haematogenous route of spread [10]. Prognosis is extremely poor after the diagnosis of distant metastasis [10-12]. The only patient who had not died by the end of our study follow-up period had only been diagnosed a month prior; the rest had survived not more than 9 months after the diagnosis of distant metastasis. Conventional chemotherapy has not been found effective $[3,13]$. None of the women in our study received chemotherapy. Many had been hesitant given the uncertain benefit and in fact, the disease was often rapidly progressive and death occurred soon after.

In our study, we found involved surgical margins to be the single most important factor associated with distant metastasis. The significance of surgical margins is well reported [14,15], though some have also found no association between margin clearance and survival $[16,17]$. However, it is not known how wide a margin is necessary to minimise recurrence rates $[12,18,19]$. A $1 \mathrm{~cm}$ margin clearance has been recommended [7,9], but this can be difficult to achieve even with a mastectomy as phyllodes tumours can present as very large masses. In fact, $26 \%$ of the women in our study presented with tumours greater than $10 \mathrm{~cm}$. Tumour size was found to positively correlate with distant metastasis and we had also observed that women with distant metastasis tended to present with larger tumours [20]. In 2 women, the post-mastectomy defect was too large for primary closure, further illustrating the difficulty faced with large phyllodes tumours. Despite a nationwide breast cancer screening program and public awareness activities, it is still not uncommon to see women presenting with large advanced tumours in Singapore [21]. Several authors have found radiation to reduce local recurrence rates, but unlike with the usual invasive breast cancers, radiation did not improve survival in malignant phyllodes [22-24].

Local recurrence still developed in 2 of the 3 patients who received radiation in our study, but both these women had large tumours and involved surgical margins, which rendered them at high risk of recurrence regardless. We did not find tumour size to have a significant association with distant metastasis, unlike previous studies [20,25]. Also, in contrast to others, we found no association with stromal overgrowth, atypia or mitotic index $[20,25]$. Tan and colleagues developed a nomogram to predict recurrence-free survival, based on stromal atypia, mitoses, stromal overgrowth and surgical margins [26]. Even though the nomogram was not developed specifically for distant metastasis, it is likely still relevant since recurrences are more often systemic, rather than isolated local recurrences, in malignant phyllodes. However, details of stromal overgrowth and atypia are not always included in the histology report. More recent studies have implicated aberrant expression of markers such as CD10, Axl, st6galnacii and epidermal growth factor receptor (EGFR) in malignant progression and the development of distant metastases [27-29]. Further studies will be needed to validate these findings, and the main difficulty in obtaining more conclusive results lie in the rarity of malignant phyllodes tumours.

\section{Conclusion}

Malignant phyllodes are rare cancers of the breast. Surgery is the only effective treatment modality at present, and complete resection with clear surgical margins appears to be the best predictor of a good outcome. Involved margins are associated with distant metastasis and conventional chemotherapy and radiation treatments do not appear effective. Consequently, prognosis is very poor after the occurrence of distant metastasis. 


\section{References}

1. Barrio AV, Clark BD, Goldberg JI, Hoque LW, Bernik SF, et al. (2007) Clinicopathologic features and long-term outcomes of 293 phyllodes tumors of the breast. Ann Surg Oncol 14(10): 2961-2970.

2. Buchberger W, Strasser K, Heim K, Muller E, Schrocksnadel H (1991) Phylloides tumor: findings on mammography, sonography, and aspiration cytology in 10 cases. AJR Am J Roentgenol 157(4): 715-719.

3. Guillot E, Couturaud B, Reyal F, Curnier A, Ravinet J, et al. (2011) Management of phyllodes breast tumors. Breast J 17(2): 129-137.

4. Tan EY, Tan PH, Yong WS, Wong HB, Ho GH, et al. (2006) Recurrent phyllodes tumours of the breast: pathological features and clinical implications. ANZ J Surg 76(6): 476-480.

5. Tan PH, Jayabaskar T, Chuah KL, Lee HY, Tan Y, Hilmy M, et al. (2005) Phyllodes tumors of the breast: the role of pathologic parameters. Am J Clin Pathol 123(4): 529-540.

6. Tan BY, Acs G, Apple SK, Badve S, Bleiweiss IJ, et al. (2016) Phyllodes tumours of the breast: a consensus review. Histopathology 68(1): 5-21.

7. Chen WH, Cheng SP, Tzen CY, Yang TL, Jeng KS, et al. (2005) Surgical treatment of phyllodes tumors of the breast: retrospective review of 172 cases. J Surg Oncol 91(3): 185-194

8. Belkacemi Y, Bousquet G, Marsiglia H, Ray Coquard I, Magne N, et al. (2008) Phyllodes tumor of the breast. Int J Radiat Oncol Biol Phys 70: 492-500.

9. Chaney AW, Pollack A, McNeese MD, Zagars GK, Pisters PW, et al. (2000) Primary treatment of cystosarcoma phyllodes of the breast. Cancer 89(7):1502-1511.

10. Lindquist KD, van Heerden JA, Weiland LH, Martin JK (1982) Recurrent and metastatic cystosarcoma phyllodes. Am J Surg 144(3): 341-343.

11. Reinfuss M, Mitus J, Duda K, Stelmach A, Rys J, et al. (1996) The treatment and prognosis of patients with phyllodes tumor of the breast: an analysis of 170 cases. Cancer 77(5): 910-916.

12. Sotheran W, Domjan J, Jeffrey M, Wise MH, Perry PM (2005) Phyllodes tumours of the breast-a retrospective study from 1982-2000 of 50 cases in Portsmouth. Ann R Coll Surg Engl 87(5): 339-344.

13. Morales Vasquez F, Gonzalez Angulo AM, Broglio K, Lopez Basave HN, Gallardo D, et al. (2007) Adjuvant chemotherapy with doxorubicin and dacarbazine has no effect in recurrence-free survival of malignant phyllodes tumors of the breast. Breast J 13(6): 551-556.

14. Cheng SP, Chang YC, Liu TP, Lee JJ, Tzen CY, et al. (2006) Phyllodes tumor of the breast: the challenge persists. World J Surg 30(8): 1414-1421.

15. Spitaleri G, Toesca A, Botteri E, Bottiglieri L, Rotmensz N, et al. (2013) Breast phyllodes tumor: a review of literature and a single center retrospective series analysis. Crit Rev Oncol Hematol 88(2): 427-436.
16. Onkendi EO, Jimenez RE, Spears GM, Harmsen WS, Ballman KV, et al. (2014) Surgical treatment of borderline and malignant phyllodes tumors: the effect of the extent of resection and tumor characteristics on patient outcome. Ann Surg Oncol 21(1): 3304-3309.

17. Lin CC, Chang HW, Lin CY, Chiu CF, Yeh SP (2013) The clinical features and prognosis of phyllodes tumors: a single institution experience in Taiwan. Int J Clin Oncol 18(4): 614-620.

18. Barth RJ Jr (1999) Histologic features predict local recurrence after breast conserving therapy of phyllodes tumors. Breast Cancer Res Treat 57(3): 291-295.

19. Yom CK, Han W, Kim SW, Park SY, Park IA (2015) Reappraisal of conventional risk stratification for local recurrence based on clinical outcomes in 285 resected phyllodes tumors of the breast. Ann Surg Oncol 22(9): 2912-2918.

20. Hawkins RE, Schofield JB, Fisher C, Wiltshaw E, McKinna JA (1992) The clinical and histologic criteria that predict metastases from cystosarcoma phyllodes. Cancer 69(1): 141-1417.

21. Pek CH, Tan EY, Chen JJ, Ho PW, Teo C, et al. (2012) Advanced breast cancer-are we doing enough? Breast J 18(6): 644-646.

22. August DA, Kearney T (2000) Cystosarcoma phyllodes: mastectomy, lumpectomy, or lumpectomy plus irradiation. Surg Oncol 9(2): 49-52.

23. Gnerlich JL, Williams RT, Yao K, Jaskowiak N, Kulkarni SA (2014) Utilization of radiotherapy for malignant phyllodes tumors: analysis of the National Cancer Data Base, 1998-2009. Ann Surg Oncol 21(4): 12221230.

24. Mitus J, Reinfuss M, Mitus JW, Jakubowicz J, Blecharz P, et al. (2014) Malignant phyllodes tumor of the breast: treatment and prognosis. Breast J 20(6): 639-644.

25. Kapiris I, Nasiri N, A'Hern R, Healy V, Gui GP (2001) Outcome and predictive factors of local recurrence and distant metastases following primary surgical treatment of high-grade malignant phyllodes tumours of the breast. Eur J Surg Oncol 27(8): 723-730.

26. Tan PH, Thike AA, Tan WJ, Thu MM, Busmanis I, et al. (2012) Predicting clinical behaviour of breast phyllodes tumours: a nomogram based on histological criteria and surgical margins. J Clin Pathol 65(1): 69-76.

27. Al Masri M, Darwazeh G, Sawalhi S, Mughrabi A, Sughayer M, et al. (2012) Phyllodes tumor of the breast: role of CD10 in predicting metastasis. Ann Surg Oncol 19(4): 1181-1184.

28. Tse GM, Lui PC, Vong JS, Lau KM, Putti TC, et al. (2009) Increased epidermal growth factor receptor (EGFR) expression in malignant mammary phyllodes tumors. Breast Cancer Res Treat 114(3): 441-448.

29. Ren D, Li Y, Gong Y, Xu J, Miao X, et al. (2014) Phyllodes tumor of the breast: role of Axl and ST6GalNAcII in the development of mammary phyllodes tumors. Tumour Biol 35(10): 9603-9612.

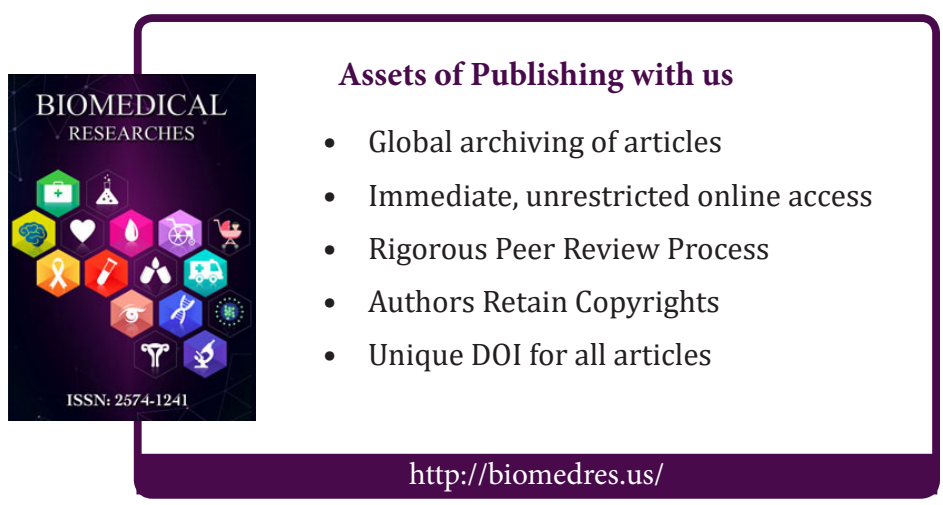

